\title{
Am I My Brain or My Genitals? \\ A Nature-Culture Controversy in the Hermaphrodite Debate from the mid-1960s to the late 1990s
}

Cynthia Kraus

\begin{abstract}
The groundbreaking and prophetic rhetoric of neuroscience has recently highlighted the fetal brain as the most promising organ for understanding why transsexuals feel "trapped in the wrong body", and for predicting whether children born with "ambiguous" genitalia will grow up to feel like a man or a woman. This article proposes a recent history of the cerebralization of intersexuality and of transsexuality as atypical neurodevelopmental conditions. It examines the ways in which the organizational theory of brain sex differentiation developed in the late 1950s in behavioral neuroendocrinology has gained increased prominence in and through controversies over best practice issues in the case management of intersex newborns, and the etiology of transsexuality. It focuses on the American context and on the leading warrior in this battle: Milton Diamond, now a most prominent figure in professional debates about the clinical management of intersexuality, and the intersex person's best friend.

Persons with an intersexed or transsexual condition consider, not their gonads, but their brains, their core sense of self, as the primary determinant of sex. (Diamond and Beh 2005, 6-7, note 1)

Keywords: brain; gender; intersexuality; transsexuality; patient advocacy; Milton Diamond
\end{abstract}

Dr. Cynthia Kraus, MER, Institute of Social Sciences, Faculty of Social and Political Sciences, University of Lausanne, Anthropole Building, Office 3087, CH-1015 Lausanne, tel +41 21 69232 23; fax: +41 216923215 (Cynthia.Kraus@unil.ch). 


\section{Dramatizing the limits of medicine}

In January 2004, the journal Nature featured an article commenting on new evidence suggesting that the fetal brain is "the most important sexual organ"more important than sex hormones, and perhaps even than sex-determining genes, for understanding how one gets to know if one is male or female early in the womb. "Does the fetal brain know its sex before its gonads [testis or ovary] develops?" That is the new research question and assumingly a most promising one for explaining why transsexuals feel "trapped in the wrong body" and want sex change operations, but also for developing a biological tool that could predict whether children born with "ambiguous" genitalia ${ }^{2}$ will grow up "thinking, feeling, and behaving like a man or a woman," and help decide which sex should be assigned at birth to prevent gender dissatisfaction at adult age ${ }^{3}$. To drive her point home, Dennis reports the case management of two genetic males with so-called ambiguous genitalia, Susan and Tony. Susan was assigned as a girl, underwent feminizing genital surgery along with hormonal treatment, and her parents were assured she would normally develop and identify as a female. And so it happened: she is now in her twenties, married and living happily thereafter as a woman. But things did not turn out as well for Tony who was also assigned the female sex - in keeping with the surgical and phallocentric dogma, unchallenged by the Nature article, that it is easier to construct a "credible" vagina than a penis. Tony always felt unhappy as a girl, turned to testosterone treatment and switched to living as a man.

Susan's successful gender assignment is consistent with a theory of gender identity formation developed in the 1950s by John Money and colleagues, in particular Joan and John Hampson, from studies on "life adjustments" by hermaphrodite infants in close collaboration with Lawson Wilkins, one of the founders of pediatric endocrinology in the 1940s, at the psychohormonal unit at the Johns Hopkins Hospital, Baltimore. According to this theory, one is not born, but becomes a man or a woman early in life: one assumes a gender identity and role through raising and social interactions, reinforcement and learning, just like one learns how to speak native language. The learning process is limited in time: gender identity is established at the critical age of

1 Dennis 2004, 391.

2 Prevalence figures vary from 0.1 to $2 \%$ depending on the varying definitions of intersexuality (Blackless et al. 2000). Not all intersex children are born with ambiguous genitalia. However, such cases are considered paradigmatic in professional literature because they raise the question of gender assignment in the most dramatic manner.

3 See Dennis 2004; see also Hines 2004, ix. 
18 months, and "indelibly imprinted" (a concept borrowed from Austrian ethologist Konrad Lorenz) by the age of two or three years ${ }^{4}$. This process is not equally plastic for candidates to masculinity or femininity: a "credible" penis is required to qualify as a boy and develop into a normal man. In theory, the importance of the external genitalia was minimized, but in practice, healthy psychosexual development was said to depend primarily on the "appearance and morphology of the external genitals"s. These genital-centered recommendations have served to rationalize surgical and hormonal treatment so as to maintain and fortify the child in assigned gender ${ }^{6}$.

Since the 1980s however, adults born with an intersex condition and treated according to Money and colleagues' recommendations have been confronting health professionals with another story: bodies mutilated by unwanted genital surgery, brainwashed minds, gender-role training, medical secrecy, family secret, shame, trauma, stigma, and the desire to get their intersexed body back or to change assigned gender. Ironically, surgical and hormonal treatment to turn intersex children into heterosexual men or women just like everyone else tends to produce dissatisfaction with assigned gender - what could be called "nosocomial transsexuality" - as an unwanted result of medical care. Despite ongoing debates in the medical community initiated by intersex associations, issues about optimal care for children born with an intersex condition, the best criteria for gender assignment, the opportunity and timing of genital surgery, informed consent and complete disclosure, have not be settled yet ${ }^{7}$. Quite to the contrary, disputes over the clinical management of intersexuality have been re-ignited by the recent controversial "Consensus statement" published in 2006 by the American Academy of Pediatrics that proposed renaming intersex conditions as DSD (disorders of sex development) and new guidelines for neonatal specialists ${ }^{8}$. The clinical promises of fetal brain sex research make sense and are advanced in this critical context - a crisis and a critique of medicine. Such research, as the Nature article suggests, might help resolve the negative outcomes of gender assignments that draw the limits of medicine so far: Susan and Tony's doctors held the wrong belief that "the brain is a sexual blank slate until it comes under the influence of sex hormones" 9 . However, brain sex research is not just a new predicting tool to improve satisfaction from patients like

\footnotetext{
4 Money/Hampson/Hampson 1955a, 310; 1955b, 285.

5 Money/Hampson/Hampson 1955a, 308; 1955b, 288.

6 Money/Hampson/Hampson 1955b.

7 See e.g. Blizzard 2002.

8 Lee et al. 2006; see also Hugues et al. 2006.

9 Dennis 2004, 390.
} 
Tony, it has been a major player in redefining the clinical issues it claims to resolve as precisely cerebral issues. In this regard, the so-called limits of medicine dramatized in the discourse of brain sex are better analyzed as a trope that serves the self-promoting rhetoric of neuroscientific progress and its claims to enlighten medical practice.

The question of an intersex and transsexual brain that extends controversial studies about the female, male and gay brain, has received little attention from brain science studies scholars, including feminist/queer critics of neuroscience and transgender theorists. This article proposes a recent history of the cerebralization of intersexuality - and, to a lesser degree, of transsexuality - as atypical neurodevelopmental conditions. It examines the ways in which the organizational theory of brain sex differentiation developed in the late 1950s in behavioral neuroendocrinology has gained increased prominence in and through controversies over best practice issues in the case management of intersexuality, and the etiology of transsexuality. The founders of the organizational theory asserted from the beginning its relevance for clinical practice. This theory was extended to the case management of hermaphroditism (as it was called at the time) and operationalized in the treatment plan defined by John Money and colleagues (see e.g. van den Wijngaard 1977). For my part, I would like to highlight another aspect of the organizational theory's success story ${ }^{10}$, by analyzing the ways in which it has been used as early as the mid-1960s as a "war machine" against Money and colleagues' conceptions of gender identity formation, that emphasized learning and raising. Central to this ongoing controversy is the question of whether gender identity formation in intersex newborns is more a function of their brains rather than of their genitals. My discussion focuses on the American context and on the leading scientist in this battle: Milton Diamond, now a most prominent figure in professional debates about the clinical management of intersexuality, and the intersex person's best friend. For a long time, however, Diamond would be rather lonely in the battlefield. His

$10 \mathrm{My}$ present discussion thus does not include the pioneering experiments reported in the Nature article earlier mentioned and new animal evidence suggesting that sexual differentiation of the brain might occur before the formation of a testis or an ovary, i.e., independently from the so-called sex hormones produced by the gonads. This latest development calling into question the classic hormone-centered model of sexual differentiation of the brain falls outside the limits of this article, as intersexuality and transsexuality were brained within this classic framework, i.e., when "the field was completely dominated by hormone people"(Vilain quoted in Dennis 2004,391). Eric Vilain, one of the two scientists interviewed by Dennis, is a geneticist specialized in sex determination. Interestingly, Vilain was part of the medical board of the Intersex Society of North American (ISNA) and one of the experts consulted for the Consensus Statement (see Hughes et al. 2006). 
blows did not strike home until intersex adults began to challenge the medical community and went political during the decade of the brain ${ }^{11}$.

\section{Cerebral arguments in the John/Joan case}

Patient dissatisfaction with standards of care came to medical attention with the reevaluation of the so-called John/Joan case ${ }^{12}$ reported in an article published by biologist Milton Diamond and psychiatrist Keith Sigmundson in Archives of Pediatric and Adolescent Medicine ${ }^{13}$. The subject is a 7-month normal boy, Bruce Reimer, who had lost his penis in a circumcision accident and was referred in the late 1960s to the psychohormonal unit at the Johns Hopkins Hospital. In keeping with the Baltimore treatment plan for hermaphrodite infants, the boy without a penis was surgically reassigned as a girl just before two years. Joan (real name Brenda, formerly Bruce) was raised as a girl and grew up not knowing she was born male. Money and colleagues at the time looked confident that she had accepted living as a girl and would develop a normal female gender identity, unlike his "control" twin brother Brian $^{14}$. In their 1997 follow-up study, however, Diamond and Sigmundson revealed that Joan had switched back to living as a man since the age of 14 years, after a long period of distress and the eventual disclosure by his father about what happened. John (chosen name David) is described as a psychosexually healthy, socially adapted and self-respecting man, husband, and father of two adopted children. ${ }^{15}$

The reasons for John's desire to return to a masculine identity are discussed at length in the article based on the reevaluation of the medical reports at the time, interviews with his mother and twin brother, with special truthvalue given to John's experience and self-description of his feelings, physical looking, behavior, as well as activity, toy and clothing preferences. Diamond and Sigmundson underscore the fact that John always felt uncomfortable as a girl, and was constantly admonished and mocked at as un-girly. Most importantly, his typically masculine behavior was mistakenly regarded as

11 Shorter and modified versions of this story are presented elsewhere to illustrate a programmatic proposal I have made for feminist/queer brain science studies scholars to work with a critical framework centered on controversy and conflict analysis (Kraus, 2011), i.e., with a "dissensus framework" (Kraus, 2012).

12 The case was named after the pseudonyms given to the subject at different moments of his life - and no doubt an ironical hint at John Money, John and Joan Hampson.

13 Diamond/Sigmundson 1997a.

14 Money/Ehrhardt 1972; Money 1973; Money 1975.

15 On May 11, 2004, Bruce/Brenda/David Reimer committed suicide. See e.g. "David Reimer, 38, Subject of the John/Joan Case, Dies", www.nytimes.com/2004/05/12/international/americas/12REIM.html (accessed 21 August 2009). 
tomboyish, instead of being read as irrepressible manifestations of his true sex. In their account, John's private and public experience of self is fundamentally dramatized as the story of a boy who was made into a girl but never felt like a girl and became the man he was born as.

"I suspected I was a boy since the second grade [between 9 and 11 years]" says John ${ }^{16}$. The authors take the position to believe that John is what he says he is - against medical expectations. How did he figure out he was not a girl, despite the absence of a penis, despite the fact he was raised as a girl, acknowledged this status, and ignored he was born a normal male until the age of 14 years? The answer is: John recognized the male in himself ${ }^{17}$. This recognition comes from without "due to an analysis of one's inner feelings and behavior preferences in comparison with those of one's peers"18. But it also comes from within: John's feelings of self as male indicates that individuals are not "psychosexually neutral" as assumed by Money and colleagues, but psychosexually biased, i.e. prenatally predisposed to becoming the man or woman one is born as and act accordingly ${ }^{19}$. In John's case, his innate preferences were thwarted in a dramatic manner ${ }^{20}$.

In truth, the significance of the brain is suggested only in passing and rather downplayed by the authors themselves: "The last decade has offered much support for a biological substrate for sexual behavior. In addition to the genetic research mentioned, there are many neurobiological and other reports that point in this direction." 21 We do not learn much more either, when they introduce us to a theory Diamond coined PRIMO in the 1970s, since

16 Quoted in Diamond/Sigmundson 1997a, 300.

17 See Diamond 2000, 4/ 8.

18 Diamond 1997, 205.

19 Diamond/Sigmundson 1997a, 302.

20 Feminist scholars have, of course, critiqued Diamond and Sigmundson' naturalistic interpretations as well as the violent enforcement of gender malleability imposed to Bruce/ Brenda/David by the Baltimore team. By contrast, they have proposed social constructivist analyses of the ways in which the normative matrix of gender about sex and identity is constitutive of subject formation and self-narratives like John's, enabling him to make sense of his life, actively producing his inner sense of self as a man in the disciplinary frame of medical discourse (see, e.g., Hausman 2000; Butler 2006, 75-93). The problem or limits of current feminist analyses of the John/Joan case is that they tend to obscure the most important fact that John's feelings of self as male are not said to arise from his Y chromosome (as assumed by Butler 2006, 81) or "male hormones" per se, but from their organizational effects on his brain. A male-direct brain: that is John's state of mind. The argument of a male "mindset" emerging from a brain sexed during embryogenesis in the male direction under the influence of the so-called sex hormones is a neurocentric argument. Löwy (2003) and Karakazis (2008) mention Diamond's brain-based theory. But Löwy mistakes "innateness" to mean "biological invariance" (Löwy 2003, 88, emphasis added), which is precisely not assumed by neurobiologists nor by Diamond for this matter; the problem remains with Karakazis, who considers Diamond's theory to be a "hardwire theory" (Karkazis 2008, 63-77). This point is further discussed below.

21 Diamond/Sigmundson 1997a, 303; emphasis added. 
the full details of the theory are not exposed. The authors invoke it, however, to explain how Money and colleagues' theory has, in practice and at John's expense, failed at all levels ${ }^{22}$. Yet, the authors give us a first clue when they make explicit reference to the most controversial studies by Levay (1991) and Levay and Hamer (1994) involving the hypothalamus in sexual orientation $^{23}$.

Although it is not stated as such, there is no doubt, however, that sexual identity is, just like sexual orientation, a function of prenatal neural dispositions and that John was led to recognize the male in himself because of his brain. Indeed, PRIMO is itself an elaboration of an early theory. In 1965, Diamond formulated a "sexuality-at-birth" theory with the explicit aim to contradict Money and colleagues' "neutrality-at-birth" theory, in which he gave ontogenetic precedence to prenatal neural dispositions to explain how one becomes the man or woman one is born as: "At birth, the individual may be considered to have been neurally predisposed by genetic and hormonal means toward one sex." ${ }^{24}$. Fifteen years later, a BBC follow-up of the "twincase" (as the John/Joan case was called at the time) and a related paper would provide Diamond with the first opportunity to make a public case against Money and colleagues and question the successful outcome of their assignment of Bruce Reimer, the boy who had lost his penis, to the female gender. ${ }^{25}$ In the John/Joan case, Diamond restates his positions about a fetal brain sex, but, unlike his earlier papers, it soon became a reference in professional debates about the clinical management of intersexuality. Even if Bruce/ Brenda/David Reimer was not born with any hermaphroditic condition, but a normal boy with traumatized genitalia, the John/Joan case can be considered a "foundational story" in contemporary neurobiological discourse about intersexuality and in the growing public awareness about this issue.

22 Diamond/Sigmundson 1997a, 302.

23 Diamond/Sigmundson 1997a, notes 50 to 56.

24 Diamond 1965, 165.

25 Diamond 1982. It is worth mentioning here that the BBC follow-up and Diamond's article were produced in the context of a controversy over the relative importance of psychological and biological factors in gender identity formation. The preeminence of prenatal sex hormones was asserted anew in studies conducted in Santo Domingo on so-called "penis-attwelve" boys who were raised as girls, but who assumed a masculine identity and role at puberty (Imperato-McGinley et al. 1974; 1976; 1979). The authors of these studies drew two main conclusions against Money and colleagues' theory: first, "gender identity is not fixed in early childhood but is continuously evolving and is not alterably fixed in childhood but is continually evolving;" second, "when the sex of rearing is contrary to testosterone-mediated biologic sex, the biologic sex prevails" (Imperato-McGinley et al. 1979, 1235-36, quoted in Fausto-Sterling 1992, 87, who discusses these studies in more detail). For lack of space, I cannot either discuss here an important controversy that took place earlier, in 1970, between Bernard Zuger against John Money in Psychosomatic Medicine. For a discussion, see FaustoSterling (2000, 68-69); Castel (2003, 75-82). 
It received extensive media coverage as evidence that nature rather than culture is the most important factor in gender and sexual identity formation ${ }^{26}$.

Since the John/Joan case, Money and colleagues' theory has been repeatedly presented as a theory about the "social construction of gender" to the complete exclusion of biological factors. While this theory definitely emphasizes the preeminence of psychological factors, it does not simply do away with biology: data from embryology, endocrinology, genetics and neurobiology is systematically examined, discussed, and even involved in the establishment of gender identity through life experiences: "psychosexual (or gender identity) development of sex is a continuation of the embryo-

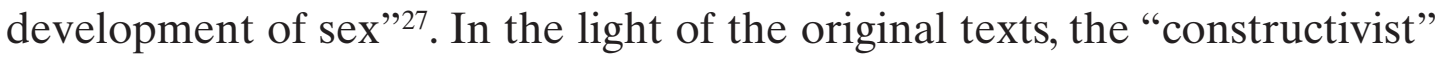
picture of psychosexual theory is itself an effect and a precondition to construct a theoretical and professional antagonism between two interactionist frameworks that both sought, at the time, to overcome the false nature-nurture divide ${ }^{28}$.

\section{The body/genitals of one sex, the brain of the other}

At the time, Diamond inferred John's male mindset from controversial studies about sexual orientation involving the human hypothalamus ${ }^{29}$, but his argument was "confirmed" by concurring studies on the "transsexual brain." In 1995, the journal Nature published the first study "to show a female brain structure in genetically transsexuals and supports the hypothesis that gender identity develops as a result of an interaction between the developing brain and sex hormones" ${ }^{\prime \prime}$. Based on post-mortem observations of brain tissue from six male-to-female transsexuals (M2F), the authors conclude that a site of the hypothalamus called BSTc (central subdivision of the bed nucleus of the stria terminalis) is dimorphic in relation to gender identity (Diamond

26 See in particular Colapinto 2000.

27 Money/Ehrhardt 1972, 1. Van den Wijngaard (1997) considers that Money and Ehrhardt's 1972 book played a major role in establishing the organizational theory as an "obligatory point of passage" for anyone involved in investigations of masculinity and femininity in behavior (35). In her study of the organizational theory focusing on the years 1959-85, she distinguishes three main periods in Money and colleagues' work: "In 1955, before the appearance of the organization theory, John Money and his colleagues, who worked with intersexes, saw masculinity or femininity in behavior as the result of experiences of growing up. By 1972 they had modified that position: Male and female behavior became at least partly the result of hormone bathing of the brain"; "In 1980, Money no longer presented the effects of androgens before birth as direct causes of femininity and masculinity, but as tendencies toward masculine or feminine development" (van den Wijngaard 1997, 83, 90).

28 See, e.g. Money/Hampson/Hampson 1955a, 309; Money 1981, 97.

29 Levay 1991; Levay/Hamer 1994.

30 Zhou et al. 1995, 68 . 
would speak of sexual identity) rather than sexual orientation: BSTc is small in individuals who feel female - heterosexual and homosexual women and $\mathrm{M} 2 \mathrm{~F}$ - but large in individuals who feel male - heterosexual and homosexual men and, supposedly, female-to-male transsexuals (F2M). The size of BSTc does not vary with hormonal levels at adult age, excluding the hypothesis that the female-size of the M2F might be an effect of feminizing hormonal treatment; hence, sexual dimorphism in BSTc size must depend on brain development in the womb. A subsequent study suggested that M2F had a "female number of neurons" at the BSTc site, while the single F2M in the pool had a "male number of neurons," that is, twice as much as women (heterosexual or homosexual) and $\mathrm{M} 2 \mathrm{~F}^{31}$. Others studies have popped up since then.

Three elements are noteworthy, and I will discuss them in relation to the 1995 pioneering article. First, this study refers to earlier research involving the hypothalamus in sexual orientation; yet, it precisely seeks to identify a site that does not vary according to erotic partner choice, but varies according to one's feelings of self as male or female - regardless of genital sex and assigned gender ${ }^{32}$. Second, this definition of transsexuality as a mismatch between gender identity and anatomical sex, brain and body, and the desire to reconcile the two, is obviously an incarnation of the current psychiatric category of Gender Identity Disorder (DSM-IV-TR 2000). Such studies however construct a perfect adequacy, a cause-to-effect relation between brain and mind: the feeling of self as male or female is said to arise from the brain. Third, the authors of the first study on the transsexual brain acknowledge earlier debates about the "psychogenic or biological etiology of transsexuality" and present John Money as the main tenant of the psychogenic thesis ${ }^{33}$. Their research question and interpretation of data are set against this theoretical background ${ }^{34}$.

31 Kruijver et al. 2000, 2034.

32 Zhou et al. 1995, 68.

33 Zhou et al. 1995, 68.

34 John Money (as well as psychologist Anke Ehrhardt, a former doctoral student of Money, psychoanalyst Robert Stoller, and psychiatrist Robert Spitzer, who was instrumental in eliminating Homosexuality as a mental disorder) contributed to frame the psychiatric diagnosis of Transsexualism, introduced for the first time in 1980 into the DSM-III as a Gender Identity Disorder (GID) under the larger class of Psychosexual Disorders - a name chosen on purpose: "The name of this class emphasizes that psychological factors [in particular disturbed family context and parent-child relationship] are assumed to be of major etiological significance in the development of the disorders listed here." (DSM-III 1980,261, emphasis added). In fact, it is worth underscoring that the hypothesis of a neurobiological etiology is not excluded per se (see e.g. Money 1981, 128). However, his research emphasis and theoretical commitments make him favor a psychological etiology, just like other experts at the time. 


\section{Intersexing the brain}

In the light of such studies, Milton Diamond claims nothing but that transsexuals are in fact intersexed. This is a most important claim that deserves closer scrutiny. Diamond's first explicit statement seems to appear in 1997:

"Zhou, Hofman, Goreen, and Swaab (1995) and Swaab and Hofman (1995) documented differences in the brain of transsexual individuals. Transgendered individuals might be considered intersexed, not with ambiguous genitalia, but in regard to their brain structure and function." 35

Since Diamond assumes that individuals diagnosed with Gender Identity Disorder (GID) have the brain of one sex and the body of the other, one could argue that he does not intersex transsexuality, but quite to the contrary transsexualizes intersexuality. It seems to me that this interpretation would be mistaken, because this would involve assuming rather than analyzing the clinical terms in which both intersexuality and transsexuality are currently defined and managed. To be more precise, intersexuality is in effect transsexualized in the case of individuals who, like Tony in the Nature article, are dissatisfied with their assigned gender at birth and want to change it. But it is so because gender dissatisfaction and gender change are, in theory and practice, constructed as a mental disorder (current and prevailing psychiatric conception) or as psychological distress or existential suffering (psychosocial non-psychiatric mental health issue compatible with a neurobiological etiology). Given the current state of affairs, transsexuality becomes a reference framework recruited to think and "correct" the bad outcomes resulting from the clinical management of intersexuality ${ }^{36}$. The latest recommendations

35 Diamond 1997, 207, emphasis added; see also 2000, 48; 2002b, 5/31; 2009, 629.

36 In the diagnosis of Transsexualism (DSM-III) up to the current nomenclature (the term Transsexualism was eliminated since the DSM-IV), GID is not diagnosed for individuals born with an intersex condition: "The absence of physical intersex of genetic abnormality" is a diagnostic criterion of Transsexualism; "In physical intersex the individual may have a disturbance in gender identity. However, the presence of abnormal structures rules out the diagnosis of Transsexualism" (DSM-III, 263; 264, emphases added). Yet, intersexed individuals who reject their assigned gender can access sex change treatments via the specific diagnosis of GID "Not Otherwise Specified" (DSM-IV-TR, 550). Although studies on the transsexual brain do not make it explicit, they involve redefining transsexuality as a "disorder of sex development" (DSD), which is precisely the new medical terminology adopted for intersexuality in 2006, since the ancient and "freak" categories of hermaphroditism had been eliminated from professional usage (see Lee et al. 2006; Hughes et al. 2006). In this light, the fact that the revised diagnosis and terminology of "Gender Incongruence" (instead of GID) proposed in the DSM-V (in progress) now comes in two versions - without and with a DSD condition - registers no surprise. Boundary work between intersexuality and transsexuality, as well as the existing tensions between intersex activists that demand less/no surgery and hormonal treatments, and transsexual people who ask for (a more) open access to these technologies, are complicated issues that cannot be developed here. 
of the American Academy of Pediatrics for the "psychosocial management" of intersexed children are telling in this regard ${ }^{37}$.

Lately, the brain-body relation assumed in studies on the "transsexual brain" has been conceived as a sex reversal, a technical term used in the field of sex determination research precisely to define intersex individuals ${ }^{38}$. Sex reversal can be either complete (typically "normal"-looking females with an XY "male" karyotype or "normal"-looking males with an XX "female" karyotype) or partial (as in the case of XY males with cryptorchidism, micropenis or hypospadias). The term "sex reversal" seems to appear for the first time in the 2000 BSTc study:

"The present findings of [...] neuronal sex differences in the BSTc and its sex reversal in the transsexual brain clearly support the paradigm that in transsexuals sexual differentiation of the brain and genitals may go into opposite directions and point to a neurobiological basis of gender identity disorder."'39

As counter-intuitive as it may seem and contrary to neuroscientific literature, the notion of a transsexual brain is rather a misnomer: it involves in fact an intersexed brain-body relation, a sex reversal between brain sex and genital sex, in sum a brain-body sex reversal. Most importantly, the so-called transsexual brain is not only intersexed according to this developmental definition, it has an intersex-centered history in which Diamond has been an active promoter of a single kind of atypical brain, but also a pioneer in this matter.

\section{Braining intersexuality}

As early as 1965, Diamond suggests that hermaphroditism (the term used at the time) involves atypical brain development. As we have seen, Diamond's "sexuality-at-birth" theory is explicitly presented as a biological refutation of the so-called "neutrality-at-birth" theory developed by Money and colleagues. Diamond's contradicting thesis is that one is born with an innate sexual identity, i.e., predispositions that are tied up to the development of a brain sex in the womb. The brain is sexed in a dimorphic fashion under the influence of prenatal hormones directing sex development in the whole body. At the time however, Diamond's "sexuality-at-birth" is not grounded in any human evidence, but inferred from animal studies on sex development ${ }^{40}$.

37 Lee et al. 2006, e492-e493.

38 For an overview, see Chadwick/Goode 2002; see also Wilkie et al. 1993.

39 Kruijver et al. 2000, 2064, emphasis added.

40 Diamond 1965, 161. 
To be more precise, Diamond refutes the validity of the "neutrality-at-birth" theory by extending insights from the organizational theory of brain sex differentiation to discussions of human hermaphroditism. This theory was developed in the late 1950s from animal studies in behavioral neuroendocrinology by William C. Young, one of the founders of the field and who established some of its core principles - with or independently from Robert W. Goy, Charles H. Phoenix, and Arnold A. Gerall, at Young's laboratory at the University of Kansas ${ }^{41}$. When Diamond writes his 1965 paper, he is conducting animal research in the same laboratory ${ }^{42}$. Goy, Phoenix, and Gerall are acknowledged as his mentors at the time, and it seems that Goy suggested Diamond write the 1965 article $^{43}$.

In some classic animal experiments, the Young team has shown that prenatal hormones organize, i.e. have permanent effects on, sexual/mating behavior (mounting as male-typical behavior, lordosis as female-typical behavior) and somatic development (measured by a male or female morphology) in specific ways ${ }^{44}$. The experiments and results can be summarized as follows: when fetuses where exposed early in development to hormones of the "opposite sex," the morphology of the genetic male animals were feminized, including their genitalia, while the morphology and genitalia of the genetic females were masculinized. In these animals, sexual behavior was however not altered, genetic males were mounting, and lordosis was observed for genetic females. When fetuses were exposed at a later stage to hormones of the "opposite sex," their morphology was not altered, but in line with their genetic sex. However their sexual behavior was altered: genetic females displayed mounting-like behaviors, while genetic males were displaying lordosis-like behaviors. These original observations established two core principles of behavioral neuroendocrinology: first, that genes and prenatal hormones organize in a dimorphic fashion the "neural tissues mediating sexual behaviors" and the morphology of the whole body ${ }^{45}$; second, while the two processes occur in parallel in normal development ${ }^{46}$, in atypical brain

41 And, since 1964, at the Oregon Regional Primate Research Center: see van den Wijngaard 1997, 27, 30.

42 See e.g. Diamond/Young 1963.

43 See also Diamond 2002,3/31;2009, 622, note 1 .

44 See in particular Phoenix et al. 1959; Phoenix 1961; Young et al. 1964.

45 Phoenix et al. 1959, 369.

46 The organizational theory was explicitly formulated in analogy with Alfred Jost's experiments on sexual differentiation of the genital tracts in the early 1950s, and this analogy is one of the reasons for the relatively easy acceptance of the new hypothesis that prenatal hormones had organizing, i.e. permanent, effects on the fetal brain. For a more detailed discussion, see van den Wijngaard 1997; see also Fausto-Sterling 2000, 195-232. 
and body development, "the brain and the genitals can be differentiated and develop independently" 47 .

This neurodevelopmental "antagonism" between brain and genitalia, between brain and body, is precisely a fundamental postulate in current research on the so-called transsexual brain: it was shown (initially by the Young team) that "the same gonadal hormones that prenatally determine the morphology of the genitalia also influence the morphology and function of the brain [...] in a sexually dimorphic fashion. This led to the hypothesis that sexual differentiation of the brain in transsexuals might not have followed the line of sexual differentiation of the body as a whole." ${ }^{48}$ From such studies, as we have seen, Diamond suggests that transsexuals are intersexed in relation to their brain: their whole body is either male or female, to the exception of their brain which has not been sexed accordingly. Now, hermaphroditic individuals are "male and female combinations in body and mind," and since the mind, in the neurobiological paradigm, arises from the brain, from such a perspective, it means that their brain too is "somehow altered in their neurophysiological capacity towards or away from certain features of sexual behavior." 49 However this alteration does not define an "intersexed brain." Rather hermaphroditic individuals turn out to be bisexual in relation to their brain ${ }^{50}$.

In his 1965 paper, Diamond assumes an "inherent neural bisexuality," a postulate that was already spelled out by the Young team in their initial paper $^{51}$. In the light of their neuroendocrinological and behavioral data, they suggest however that: "In the adult this bisexuality is unequal in the neural tissue as it is in the case of the genital tissues. The capacity exists for giving behavioral responses of the opposite sex, but it is variable and, in most mammals that have been studied and in many lower vertebrates as well, it is elicited only with difficulty." ${ }^{, 2}$ In short, this means that the brain develops as male or female out of a primordial bisexuality, a claim that both assumes and challenges the idea of two mutually exclusive sexes. The notion of an inherent neural bisexuality underwrites the notion of neural predisposition

47 Diamond 2002, 28/31.

48 Zhou et al. 1995, 68.

49 Diamond 1965, 166.

50 This is probably a "trace" of the ways in which the theory "about a basic bisexuality of the brain" developed in the mid-1940's by Frank Beach, the most vocal opponent to the organizational theory (see footnote 60 below), is incorporated and reformulated in the latter. By the mid-1970s however, Beach will eventually accept the idea that prenatal hormones can produce permanent (and not only temporary) effects on the fetal brain. For a more detailed discussion, see van den Wijngaard 1997, 39-40; Fausto-Sterling 2000, 218-219.

51 Phoenix et al. 1959, 380.

52 Phoenix et al. 1959, 381; also quoted in Diamond 1965, 148. 
towards one sex: from a developmental point of view, it is an early potentiality, as the embryo is said to be sexually bipotential or undifferentiated until the sixth-eighth week of gestation,i.e., until gonadal differentiation. This primordial bipotentiality - or bisexuality to use the Young team's term - is then restricted in two ways. First of all, the individual is predisposed towards one sex from within, i.e. prenatally under the influence of genes and hormones. As s/he grows up, the individual's innate neural predisposition may be restricted from without according to the gender variations tolerated in a given society and at a given time. The two developmental processes, before and after birth, work together and make it possible for an individual to assume a variety of gender identities and roles. However, variations in the gender identities and roles an individual can assume are ultimately a function of how much flexibility is allowed by one's in-built predispositions, predispositions that are tied up to brain sex development. Diamond distinguishes several critical stages in psychosexual development: "This inherent sexuality, like other biological characters, need not necessarily manifest itself at birth as it might be first revealed at puberty or during adulthood. Nevertheless, inherent sexuality may, from birth, provide a built-in 'bias' with which the individual interacts with his environment." ${ }^{53}$ On this account, Diamond infers that hermaphroditic individuals have somehow retained this inherent neural bisexuality, hence the idea of a bisexual brain that may go either way, or one way and the other before and after puberty - even if it goes against social expectations. For these reasons, it is difficult to predict whether such individuals will grow up to feel and identify as male or female.

Diamond's brain-based theory of psychosexual development has two main clinical implications. First, "since the human brain is sexually dimorphic, it is not always possible to predict whether the adult will be happy with their gender 20 or 30 years after such critical decision has been made in the first days of life" 54 . Second, and most importantly for our following discussion, the developmental "antagonism" between the brain and the genitalia outlined in animal studies at the time is a neurobiological fact that underwrites Diamond's opposition to early genital surgery in the late 1990s: braining intersexuality involves de-genitalizing sex development, sexual identity and orientation altogether. In sum, I am my brain sex rather than my genitals (see also introductory quote). In hindsight, it seens obvious that Diamond would have been an ideal candidate for an alliance with intersex activists 
seeking to put an end to unwanted genital surgery. In 1965, the birth year of Bruce/Brenda/David Reimer, the subject of the John/Joan case, it is however as a biologist trained in behavioral neuroendocrinology that Diamond responds to theories that privilege socialization over our mammalian heritage. His intervention in the hermaphrodite debate seeks to rehabilitate "more classic notions of inherent sexuality at birth" 55 , and appears in this regard as a professional statement:

"The zeitgeist at the time held that it was rearing that most determined basic sexual behaviors such as whether individuals would act as males or females and towards which others they would be sexually attracted. It is within this framework that we asked if the factors that determined behavior were more in the upbringing or in the biology with which the individual is born." 56

Diamond's 1965 article entitled "A critical evaluation of the ontogeny of human sexual behavior" is in fact a direct response to a paper by the Hampsons, "The ontogenesis of sexual behavior in man," published in the 1961 edition of Sex and Internal Secretions, the major endocrine reference at the time. This volume edited by William Young opens up with an article by the latter, "The Hormones and Mating Behavior," and also includes a contribution by John Money on "Sex hormones and other variables in human eroticism." Since the John/Joan case, professional and public debates about the clinical management of intersexuality obscure the fact that the Young team and Money and colleagues' respective theories were initially not rival ones, and even less so over the years as Money and Ehrhardt in particular played a major role in introducing the organizational theory into clinical practice ${ }^{57}$. The Young team suggested from the outset the relevance of their theory "which is ipso facto important for psychologic and psychiatric theory" Compared to current debates, the tone at that time is more of a scientific conversation between the two disciplines studying the "ontogenesis of sexual behavior" - apparently to the relative advantage of psychology: "We [neurologists] may speak of shaping the behavior by hormone administration just as the psychologist speaks of shaping behavior by manipulating the external environment" ${ }^{\prime 9}$. By contrast, Diamond's first intervention in the

55 Diamond 1965, 148.

56 Diamond 2002,3/31.

57 Money/Ehrhardt 1972. For this reason, it makes sense to qualify Money and colleagues' theory of conditioning/imprinting - by 1972 - as an expression of "endocrinal behaviorism," a framework that has been instrumental to the institutional recognition of the field of sexology (Castel 2003, 56).

58 Phoenix et al. 1959,370, emphasis added.

59 Phoenix et al. 1959, 381, emphasis added. 
hermaphrodite debate takes a much more polemical stance, declaring a "science war" against psychology and the more recent field of sexology ${ }^{60}$. Yet, the blow did not strike home, and for long, Diamond would be rather lonely in the battlefield. He remained in fact a minor figure in the hermaphrodite debate, until intersex associations went political in "the decade of the brain."

\section{Our bodies, ourselves}

Intersex support and advocacy groups emerged beginning of the 1980s in North America and in Europe on the initiative of parents (mostly mothers) and adults born with an intersex condition: The Turner Syndrome [45, X] Society of Canada (1981; 1987 in the U.S.); The Androgen Insensitivity Syndrome Support Group in the U.K. (1988); The Klinefelter Syndrome [47, XXY] Support Group in the U.S. (1989); The Intersex Society of North America (ISNA) from 1993 to 2008, Organization Intersex International since 1998 and Bodies Like Ours (2000) both founded by ex-members of ISNA - to name only a few in English-speaking countries.

Among all, ISNA founded by Cheryl Chase has been the most influential in defining the intersex agenda over the last two decades ${ }^{61}$, the most present in the media, and the most cited in medical and academic literature, and the first to take an overtly political stance. Outside the intersex community, early allies of ISNA had been feminist, gay and lesbian, queer and transgender scholars and activists. ${ }^{62}$ In the context of a new wave of scholarship about gender and sexualities, and in working relationship with queer, transsexual

60 In fact, rather than Money and colleagues, the "primary critic [of the organizational theory] was Frank Beach, chair of the Psychology Department of the University of California at Berkeley" (van den Wijngaard 1997, 33; see also footnote 57 above). Beach was a most important figure in this field. Since the 1930s and during the 1940s, he had conducted brain research in rats and studied the effects of hormones on their sexual behavior. Alfred "Kinsey repeatedly cited Beach's animal studies in order to locate human behavior with the panoply of normal mammalian biology" (see Fausto-Sterling 2000, esp. 206-211). But according to van den Wijngaard, Beach contested the possibility of extending this theory to human behavior, at least, in the way Money and Ehrhardt (1972) did, because he "believed that sexual behavior was rooted in the sensitivity of the genital organs and should be seen as the outcome of pleasurable sexual experience rather than the outcome of differentiation of the brain" (van den Wijngaard 1997, 38-39).

61 In Spring 2008, ISNA dissolved and Cheryl Chase with some ex-ISNA members founded a new organization called Accord Alliance to bring professionals to put into practice the latest guidelines of the 2006 "Consensus Statement on Management of Intersex Disorders" (Lee et al. 2006; Hughes et al. 2006).

62 The most cited works on intersex groups' websites are those by feminist biologist AnneFausto Sterling, social psychologist Suzanne Kessler (1990;1998), and historian Alice Dreger $(1998 ; 2000)$ who can be considered as ISNA's "theorist" and its most legitimate non-intersexed spokesperson to address the medical community. 
and transgender movements, but also more mainstream gay and lesbian organizations, ISNA's focus, unlike the support groups existing at the time, was to politicize intersex issues in non-medical terms "in order to destabilize more effectively the heteronormative assumptions underlying the violence directed at our bodies" $"$.

However, the primary item on ISNA's agenda was not to change society, but to put an end to unwanted genital surgery performed on intersexed neonates to correct (medical discourse), normalize (activist discourse) their atypical bodies. Since ISNA was denouncing standards of care involving unwanted normalizing genital surgery, traumatic genital examinations, complete secrecy on the medical history, lack of information to the parents, and advocating less cutting and more talking, complete disclosure, free access to medical records, evaluation of adult outcomes, it was not an easy task to reach out medical specialists. Although ISNA would end up forming a Medical Board ${ }^{64}$ early professional reactions to intersex activism were rejections ${ }^{65}$. In the Fall of 1996, after ISNA had been refused admission to the annual meeting of the American Academy of Pediatrics (AAP), twenty intersexed people picketed in front of the conference building in Boston under the name "Hermaphrodites with Attitude" (in reference to ISNA's newsletter title) with banderoles like "Keep your scalpels off intersexed kids" or "Silence $=$ Death" ${ }^{\circ 6}$. In response to this protest, the AAP felt compelled to issue the following statement to the press: 'The Academy is deeply concerned about the emotional, cognitive, and body image development of intersexuals, and believes that successful early genital surgery minimizes these issues.' Further protests were planned for 1997." ${ }^{67}$

At the same time, it should be noted that despite "anti-medicine" arguments, ISNA has systematically endorsed the prevailing discourse of physical and mental health. In fact, all intersex groups argue that concerned individuals would be better off, if physicians were dealing with "real health issues" sometimes involved in intersex conditions, rather than the social (understand "non-medical") issue of morphological ideals, and if they were offering psychosocial management instead of the scalpel. This discourse makes sense given the activist agenda and the target-audience (neonate

63 Chase 1998, 199.

64 Such as urogenital surgeon Justine Schober (ISNA's earliest sympathizer, see Chase 1999, 203), psychiatrist and urologist William Reiner at Johns Hopkins Hospital and an early opponent to Money and colleagues, or Eric Vilain interviewed in the 2004 Nature article mentioned in the introduction (see footnote 10 above).

65 Chase 1998, 202-203.

66 Beck 1997/1998.

67 Chase 1998, 202. 
specialists) in the context of a sanitary and individual-centered society ${ }^{68}$. Over the years, ISNA has increasingly focused on health issues, and in particular on the many traumas resulting from clinical management. Along with the support groups asking for better medical care, such a health-oriented program will progressively trace the contours of an "ecological niche" 69 favoring the convergence between cerebral arguments about subject formation and activist struggles for recognition of the right to their bodies, themselves. The year 1997 marks a turning point in the history of the cerebralization of intersexuality in relation to intersex activism against unwanted genital surgery. Following on their article about the Joan/Joan case, and on the request of some medical intersex specialists, Diamond and Sigmundson published new "Guidelines for dealing with individuals with ambiguous genitalia" "70: The article outlines new recommendations which are very much in sympathy with ISNA's. They are expanded to include specific details for which sex to label children born with each type of condition. Diamond and Sigmundson emphasize that the child, rather than the parents, must be the patient, and stress avoidance of early surgery, respect for the child's wishes including privacy, autonomy, sexual orientation, change of sex role, and access to surgery. Most importantly, they emphasize peer support and, breaking with the tradition of the journal, include a long list of contact addresses for peer support groups ${ }^{71}$.

Diamond and Sigmundson's new guidelines were extremely well received by all intersex associations and the information posted on their respective websites with laudatory comments and relief to have their claims supported by an non-intersex person and an expert in the field. Along with ISNA's political work of consciousness-raising, this paper has participated to create controversies where there was previously an overall consensus about standards of care. Diamond's position papers calling for a moratorium on genital surgery and the necessity for long-term studies assessing the outcome of past interventions and to "undo the past deceptions," facing the medical professions with liability and best practice issues ${ }^{72}$ have been unanimously applauded, endorsed and circulated by intersex associations. He also seemed to have played a major role in the medical recognition of ISNA, introducing Cheryl Chase to physicians at the 1998 meeting of the American Academy

68 E.g. Ehrenberg 2010.

69 Hacking 1998.

70 Diamond/Sigmundson 1997b.

71 ISNA 1997, 3.

72 Diamond/Kipnis 1999; Beh/Diamond 2000.

73 Diamond 2004, 598, note 3. 
of Pediatrics held in San Francisco ${ }^{73}$. This account, including Diamond's major role in changing medical views, is corroborated by ISNA's positive appreciation of the latest developments (see ISNA 1999:5).

Intersex activism, which included touring the medical establishments, was beginning to pay off. Historian Alice Dreger, who has been one of the most active Board Members of ISNA and has worked in close partnership with Chase over the years, was invited as Guest Editor by the Journal of Clinical Ethic for a special issue about "Intersex in the Age of Ethics" (Dreger 1998). During the annual gathering of the Lawson Wilkins Pediatric Endocrinology Society held in Texas in April 1999, some professionals openly expressed their interrogations and doubts about past practice. This was quite a symbol, since Wilkins was the pediatric endocrinologist who had invited John Money to work at the psychohormonal unit at the Johns Hopkins Hospital. A most significant medical event took place the day before: a multidisciplinary conference sponsored by the National Health Institute on "Pediatric sex reassignment - a critical appraisal," bringing together "basic scientists, endocrinologists, surgeons, psychiatrists, psychologists and ethicists to discuss the management of the neonate with ambiguous genitalia." The purpose of the conference was "to put in place a standardized means of assessing the long term medical, social, and emotional outcomes for patients with ambiguous genitalia," in order "to produce a body of clinical work that allows for better medical and emotional management of these patients in the years ahead." 74 With respect to clinical practice, the conference seems to have prompted a change right away: "Though no intersex people were allowed to speak, by all reports the presentations dealt a major blow to surgeons' faith in the beneficence of the long-standing practice of early surgery; we have information that some attendees changed their practice immediately upon their return home." 75

Diamond views the Texas Conference as an historical event not just for intersex advocacy, but also for the advancement of a more scientific medicine: "The brain was to be recognized as a sexual organ" of a brain-based medicine for clinical discussions about optimal care for

74 I draw the quotes from the documents distributed to the conference attendees. I thank Dr Blaise-Julien Meyrat, pediatric surgeon at the University Hospital CHUV in Lausanne, Switzerland, for passing them to me. We have been collaborating on various projects since 2005 (see Kraus et al. 2008; Kraus 2012), as he does not perform sex assignement surgery on intersex newborns. For the conference proceedings, see Zderic et al. (2003). I could not identify the name of the organizers (except Snyder and Zderic), and authors of the quotes. I assume they are the editors to this volume, who are at the Children's Hospital of Philadelphia.

75 ISNA 1999, 5.

76 Diamond 2004, 599. 
intersexed children was strongly affirmed and is substantiated by the participation of leading, even pioneering, scientists in the field of neuroendocrinology in relation to sexual differentiation, identity and orientation. ${ }^{77}$ Diamond himself was not featured as a speaker, but references to his papers, and in particular to the John/Joan case, abound. To his greatest satisfaction, cerebral arguments about gender identity formation in hermaphrodite children he had been advancing since 1965 were finally reasserted in the critical context of growing acknowledgement by medical professionals of intersex associations, and the need to reflect on best practice issues. In the latest guidelines of the American Academy of Pediatrics (AAP), biological factors, and not the least the brain, are given ontogenetic precedence:

"Psychosexual development is influenced by multiple factors such as exposure to androgens, sex chromosome genes, and brain structure, as well as social circumstance and family dynamics." 78

This statement, which involves that psychosexual development begins with the fetal brain sexed under the influence of sex chromosomes and hormones, is in sharp contrast with the AAP's endorsement of Money and colleagues' theoretical and practical framework a decade earlier ${ }^{79}$.

\section{Our brains, ourselves?}

In the current debates about optimal care for intersex children, Diamond's notoriety and legitimacy in the intersex community are greater than ever ${ }^{80}$. In January 2008, the German Association of Intersexed People (Verein Intersexuelle Menschen), a support group for XY women founded in 2004, honored Milton Diamond for "his years of service to the intersex community and his endless commitment to their well-being and acceptance within society." The Organization Intersex International (OII) founded by Curtis Hinkle in 1998 joined in:

"We in OII wish to express our agreement with the German Intersex people who honored him. Dr. Milton Diamond has been devoted to listening to intersexed people and working to end shame and non-consensual treat-

77 E.g., Roger Gorski, Dick F. Swaab, Julianne Imperato-McGinley, and also William G. Reiner, another active promoter of the discourse of brain sex, although a less visible figure than Diamond in the hermaphrodite debate (on Diamond and Reiner, see also Karkazis 2008, 63-86).

78 Lee et al. 2006, e489.

79 See AAP 1996, 590.

80 Including or especially in the activist groups opposing the 2006 Consensus Statement in which intersexuality is redefined as "disorders of sex development" (Lee et al. 2006; Hughes et al. 2006). See the response by Diamond et al. (2006) to the new nomenclature and the thankyou letter to Diamond by Hinkle (2006). 
ments. He is a pioneer and advocate for the intersexed who has touched the lives of so many intersexed people all over the world." 81

The importance of Diamond's work to revise standards of care is unquestionable. And yet, it is precisely in this manner, i.e. through the activist backdoor, that neurocentric arguments about gender identity formation has gained increased relevance for the clinical management of intersexuality during the decade of the brain. Regardless of their political program and affiliation, intersex activists have, wittingly or not, contributed to promote the discourse of brain sex, as they have repeatedly invoked Diamond's expertise to voice the right to bodily integrity and self-determination. As it happens, the expert has been speaking the language of brain sex all the way long, including in his position papers opposing unwanted genital surgery, outlining new guidelines for gender assignment, and facing professionals with new practical, ethical and legal questions. The following quote (among others) is telling in this regard:

"The sex of assignment, when based on the nature of the diagnosis rather than only considering the size of functionality of the phallus, respects the idea that the nervous system involved in adult sexuality has been influenced by genetic and endocrine events that will most likely become manifest with or after puberty." $\$ 2$

The quote makes clear that the discourse of brain sex is offered as an alternative to the genital-centered clinical recommendations inherited from John Money and colleagues. Intersex activists' understandable focus on putting an end to unwanted genital surgery and changing standard practice with Diamond's scientific and public support has obscured a most important fact: his commendable position against surgical sex assignment and in favor of a subject-centered medicine derives from his commitment to a brain sex. As we have seen, the recent history of the cerebralization of intersexuality is the history of a biological alliance bringing together neuroscience and intersex activism against the "limits of medicine." This biological alliance emerged in the critical context of a "science war" waged by neurobiologists and other neurophiles, with Milton Diamond at the forefront, against psychosexual "constructivist" theories of gender identification and role modeling, and of a "sex war" opposing two kinds of sex organs: the fetal brain versus the genitals.

Promoters of a brain-based clinical management of intersexuality and intersex activists challenged, separately and together, standards of care as unscientific medicine and malpractice, although not always on the same

81 www.intersexualite.org/Diamond_award.html (accessed 2 June 2009).

82 Diamond/Sigmundson 1997b, 2/9, emphasis added; see also Diamond/Kipnis 1998, 9/18; Beh/Diamond 2000: 7/44. 
grounds. As intersex activists became more vocal about the damage of past practice on their bodies and lives, claiming for the end of unwanted early genital surgery and the right of bodily integrity, neurobiology became instrumental in promoting a more compassionate and evidence-based medicine. In this controversial context, one understands why (some) intersex activists have come to mobilize, individually and collectively, the discourse of brain sex as a political resource to confront neonate specialists and translate their claims, and in particular the end of unwanted genital surgery, into best practice issues. In return, intersex activists do not necessarily buy the whole discourse of brain sex. Some do, but in their public statements, most support and advocacy groups are either agnostic (ISNA ${ }^{83}$ ), ambivalent (OII), or silent on this issue (Androgen Insensitivity Syndrome Support Group in the U.K., The U.K. Intersex Association $)^{84}$. Supporting and building on intersex activism, Diamond in particular found an opportunity to assert, theoretically and professionally, the relevance of brain sex research for the clinical management of intersexuality. Neurobiology came to do intersex politics by other means as the discourse of brain sex backed up the activist agendas to revise the treatment plan defined by Money and colleagues, and to destigmatize individuals born with an intersex condition.

But the discourse of brain sex can pass for a more scientific and compassionate medicine only to the extent that it has succeeded in redefining the clinical issues it claims to resolve on its own terms ${ }^{85}$. For this reason, it seems difficult to dissociate Diamond's opposition to genital surgery from his brainbased conception of intersexuality. As a matter of fact, the still unresolved question of genital surgery in intersex newborns and a most controversial issue today, has been a minor, then outdated, issue in the science and sex wars opposing Diamond to Money and colleagues. In the John/Joan case that pro-

83 'In our work, we find that doctors' opinions about what should count as 'intersex' vary substantially. Some think you have to have 'ambiguous genitalia' to count as intersex, even if your inside is mostly of one sex and your outside is mostly of another. Some think your brain has to be exposed to an unusual mix of hormones prenatally to count as intersex - so that even if you're born with atypical genitalia, you're not intersex unless your brain experienced atypical development. And some think you have to have both ovarian and testicular tissue to count as intersex. Rather than trying to play a semantic game that never ends, we at ISNA take a pragmatic approach to the question of who counts as intersex. We work to build a world free of shame, secrecy, and unwanted genital surgeries for anyone born with what someone believes to be non-standard sexual anatomy." www.isna.org/faq/what_is_intersex. Accessed 21 January 2009 (emphasis added).

84 The discourse of brain sex redefining transsexuality as a brain-body sex reversal (Zhou et al. 1995) has also been appealing, perhaps even more so, to transsexual activists challenging the psychiatric diagnosis of Gender Identity Disorder (since the DSM-IV). Given the current state of affairs, one understands why earning a "brain of one's own" can matter to transsexuals who are said to be "out of their mind."

85 See also and again Dennis 2004. 
pelled Diamond to the frontline of the hermaphrodite debate, the authors make it clear from the outset: the postulate that "healthy psychosexual development is dependent on the appearance of the genitals [...] has only anecdotal support," since "Money no longer holds such extreme views"86. In his 1965 "sexuality-at-birth" theory, Diamond mentions corrective surgery in case descriptions, but never takes issue with it. The real stake has always been to assert the ontogenetic precedence of prenatal neural predispositions to explain why an individual will grow up to feel, think, and behave (more) like a man or a woman. The biological alliance between the discourse of brain sex and intersex activism against unwanted genital surgery was made possible, in part, by this quid pro quo.

While the discourse of brain sex supports intersex (and transsexual) claims for the right to be (true to) themselves and nobody else, to stay as they are born or change their body if they want to, the flip side of this discourse is more problematic. First of all, to be oneself is also and fundamentally a political injunction in contemporary Western societies in which self-realization and autonomy are valued; new kinds of brain and brain-based personal identities are produced and make sense in this larger context where individual and collective actors mind about social questions, frame their concerns, complaints, claims and struggles for recognition, in the language of mental health ${ }^{87}$. In this context, the discourse of uniqueness, singularity, idiosyncrasy and the like is no real critique or a way out of "medicalization" to "emancipation" and self-determination. It is a common language spoken by many, e.g., intersex activists and neurobiologists as we have seen, but also feminist, queer and transgender theorists/activists, or health care professionals promoting a subject-centered medicine, e.g., from a bio-psychosocial perspective. The rhetoric of the self is consistent not only with the classic feminist argument that the personal is political, but also with the fact that the political has itself become personal. The ways in which Diamond was able to promote the discourse of brain sex as a "war machine" against Money and colleagues, but in favor of intersex rights can be considered an interesting and recent expression of the "personal turn" in science and politics that epitomizes the longer success story of the self in American history, and of methodological individualism in scientific accounts of the relations between the individual and society across the disciplines ${ }^{88}$.

86 Diamond/Sigmundson 1997a, 298, emphases added.

87 Ehrenberg 2004; 2010.

88 Ehrenberg 2010. 


\section{Acknowledgements}

I would like to thank the two anonymous reviewers for their helpful comments on an earlier draft. My thanks also go to friends and colleagues who discussed this paper at different stages: Ellen Hertz, Vincent Pidoux, Francesco Panese, Vincent Barras, and the research group "Neuroscience, clinique, sciences humaines \& sociales" at the March 5, 2010 meeting with Fernando Vidal; and to Christel Gumy for her research and bibliographical assistance from August to December 2009.

\section{Bibliography}

American Academy of Pediatrics. Section on Urology, "Timing of Elective Surgery on the Genitalia of Male Children With Particular Reference to the Risks, Benefits, and Psychological Effects of Surgery and Anesthesia”, Pediatrics 97 (1996) 590-594

American Academy of Pediatrics, "Committee on Genetics, Section on Endocrinology, and Section on Urology. Evaluation of the Newborn With Developmental Anomalies of the External Genitalia", Pediatrics 106 (2000) 138-142

American Psychiatric Association, DSM-III: Diagnostic and Statistical Manual Of Mental Disorder, $3^{\text {rd }}$ ed. (Washington D.C. 1984 [1980])

American Psychiatric Association, DSM-IV: Diagnostic and Statistical Manual Of Mental Disorders. International version with ICD-10 codes, $4^{\text {th }}$ ed. (Washington D.C. 1995)

American Psychiatric Association, DSM-IV-TR: Diagnostic and Statistical Manual Of Mental Disorders, $4^{\text {th }}$ ed. text revision (Washington D.C. 2000)

Beck, Max, "Hermaphrodites with Attitude Take to the Streets", Chrysalis: J Transgressive Gend Ident $2(1997 / 1998)$ 45-50

Beh, Hazel G./Milton Diamond, "An Emerging Ethical and Medical Dilemma: Should Physicians Perform Sex Assignment Surgery on Infants With Ambiguous Genitalia?" [web version], University of Hawaii 2000, www.hawaii.edu/PCSS/online_artcls/intersex/intersex00_ 00.html (accessed 16 January 2009)

Blackless, Melanie/Anthony Charuvastra/Amanda Derryck/Anne Fausto-Sterling/Karl Lauzanne/Ellen Lee, "How Sexually Dimorphic Are We? Review and Synthesis", Am J Hum Biol 12(2) (2000) 151-166

Blizzard, Robert M, “Intersex Issues. A Series of Continuing Conundrums”, Pediatrics 110 (2002) 616-621

Butler, Judith, Défaire le genre (Paris 2006 [2004])

Castel, Pierre-Henri, La métamorphose impensable. Essai sur le transsexualisme et l'identité personnelle (Paris 2003)

Chadwick, Derek/Jamie Goode (eds), The Genetics and Biology of Sex Determination. Novartis Symposium 244 (New York 2002)

Chase, Cheryl, "Hermaphrodites with Attitudes. Mapping the Emergence of Intersex Political Activism", GLQ: J Lesbian Gay Stud 4(2) (1998) 189-211

Dennis, Carina, "Brain Development: The Most Important Sexual Organ" Nature 427 (2004) 390-392

Diamond, Milton, “A Critical Evaluation of the Ontogeny of Human Sexual Behavior”, Quart Rev Biol 40 (1965) 147-175

Diamond, Milton, "Sexual Identity, Monozygotic Twins Reared in Discordant Sex Roles and a BBC Follow-Up”, Arch Sex Behav 11 (1982) 181-186

Diamond, Milton, "Sexual Identity and Sexual Orientation in Children With Traumatized or Ambiguous Genitalia”, J Sex Res 34 (1997) 199-222 
Diamond, Milton, "Sex and Gender: Same or Different?" [web version], University of Hawaii 2000, www.hawaii.edu/PCSS/online_artcls/intersex/sex_gender.html (accessed 16 January 2009)

Diamond, Milton, "A Conversation with Dr Milton Diamond [web version]. In The Realm Of The Phallus Palace': The Female To Male Transsexual", Dean Kotula 35-56 (Los Angeles 2002) www.changelingaspects.com/Technical/A \%20Conversation $\% 20$ with $\% 20 \mathrm{Dr} \%$ 20Milton\%20Diamond.htm (accessed 25 December 2008)

Diamond, Milton, "Sex, Gender, Identity Over the Years: a Changing Perspective", Child Adolesc Psychiatr Clin N Am 13 (2004) 591-607

Diamond, Milton, "Biased-Interaction Theory of Psychosexual Development: 'How Does One Know if One Is Male or Female?"' Sex Roles 55 (2006) 589-600

Diamond, Milton, "Clinical Implications of the Organizational and Activational Effects of Hormones", Horm Behav 55 (2009) 621-632

Diamond, Milton/Hazel G. Beh, "The Right to be Wrong. Sex and Gender Decisions" [web version], University of Hawaii 2005, www.hawaii.edu/PCSS/online_artcls/ethics/TheRight ToBeWrong.htm (accessed 16 January 2009)

Diamond, Milton/Hazel G. Beh, "Variations of Sex Development Instead of Disorders of Sex Development", Electronic Letters to Ieuan A. Hugues et al. 2006. Consensus Statement on Management of Intersex Disorders, Arch Dis Child 91 (2006) 554-563, http://adc.bmj. com/cgi/eletters/91/7/554\#2460 (accessed 24 October 2008)

Diamond, Milton/Kenneth Kipnis, "Pediatric Ethics and the Surgical Assignment of Sex" [web version],1998, www.ukia.co.uk/diamond/ped_eth.htm (accessed 25 December 2008)

Diamond, Milton/H. Keith Sigmundson, "Sex Reassignment at Birth: Long Term Review and Clinical Implications", Arch Pediatr Adolesc Med 151 (1997a) 298-304

Diamond, Milton/H. Keith Sigmundson, "Management of Intersexuality: Guidelines for Dealing With Persons With Ambiguous Genitalia" [web version], 1997b, www.ukia.co.uk/diamond/ diaguide.htm (accessed 25 December 2008)

Diamond, Milton/William C. Young, " Differential Responsiveness of Pregnant and Non-Pregnant Guinea Pigs to the Masculinizing Action of Testosterone Propionate," Endocrinology 72 (1963) 429-438

Dreger, Alice (ed), "Intersex in the Age of Ethics", J Clin Ethics 9 (1998)

Dreger, Alice D., Hermaphrodites and the Medical Invention of Sex (Cambridge, MA 2000 [1998])

Ehrenberg, Alain, «Le sujet cérébral», Esprit 11 (2004) 130-155

Ehrenberg, Alain, La société du malaise (Paris 2010)

Fausto-Sterling, Anne, Myths of Gender. Biological Theories about Women and Men (New York $1992[1985])$

Fausto-Sterling Anne, Sexing the Body: Gender Politics and the Construction of Sexuality (New York: 2000)

Hacking, Ian, Mad travelers: Reflections on the reality of transient mental illnesses (Charlottesville 1998)

Hampson, John L./Joan G. Hampson. “The Ontogenesis of Sexual Behavior in Man”, in:William C. Young (ed.) Sex and Internal Secretions (Baltimore 1961) 1401-1432

Hausman, Bernice, "Do Boys Have to Be Boys? Gender, Narrativity and the John/Joan Case", Nat Women Stud Assoc J 12 (2000) 114-138

Hines, Melissa, Brain Gender (Oxford 2005)

Hinkle, Curtis. 2006 [16 August], "Thank you very much Dr. Diamond”, Electronic Letters to Ieuan A. Hugues et al. 2006. Consensus Statement on Management of Intersex Disorders, Arch Dis Child 91 (2006) 554-563, http://adc.bmj.com/cgi/eletters/91/7/554\#2460 (accessed 24 October 2008)

Hughes, Ieuan A./Christopher P. Houk/S. Faisal Ahmed/Peter A. Lee Hughes, in collaboration with the participants in the International Consensus Conference on Intersex organized by the Lawson Wilkins Pediatric Endocrine Society and the European Society for Paediatric Endocrinology, "Consensus Statement on Management of Intersex Disorders", J Pediatr Urol 2 (2006) 148-162

Imperato-McGinley, Julianne/Luis Geurrero/Teofilo Gautier/Ralph E. Peterson, "Steroid 5aReductase Deficiency in Man:An Inherited Form of Male Pseudohermaphroditism", Science 186 (1974) 1213-1215 
Imperato-McGinley, Julianne/Ralph E. Peterson, "Male Pseudohermaphroditism: The Complexities of Male Phenotypic Development", Am J Med 61 (1976) 251-272

Imperato-McGinley, Julianne/Ralph E. Peterson,/Teofilo Gautier/E. Sturia, "Androgen and Evolution of Male-Gender Identity among Male Pseudohermaphrodites With $5 \alpha$-Reductase Deficiency", N Engl J Med 300 (1979) 1233-1237

Intersex Society of North America (ISNA), "Hermaphrodites with Attitude", The Publication of the Intersex Society of North America (Fall 1997) 1-4

Intersex Society of North America (ISNA), "Growing Acknowledgement of need for change. Hermaphrodites with Attitude", The Publication of the Intersex Society of North America (Fall 1999) 1-6

Karkazis, Katrina, Fixing Sex. Intersex, Medical Authority and Lived Experience (Durham and London 2008)

Kessler, Suzanne, "The Medical Construction of Gender: Case Management of Intersexed Infants", Signs: J Women Cult Soc 16 (1990) 3-26

Kessler, Suzanne, Lessons from the Intersexed (New Brunswick, N.J. and London 1998)

Kraus, Cynthia, "Critical studies of the sexed brain: a critique of what and for whom?", Neuroethics DOI: 10.1007/s12152-011-9107-7 (2011)

Kraus, Cynthia, "Linking neuroscience, medicine, gender and society through controversy and conflict analysis: A ‘dissensus framework' for feminist/queer brain science studies”, in: Robyn Bluhm, Anne Jacobsen, Heidi Maibom (eds.) Neurofeminism (Basingstoke 2012)

Kraus, Cynthia/Céline Perrin/Séverine Rey, in collaboration with Lucie Gosselin and Vincent Guillot «Edito: Démédicaliser les corps, politiser les identités», Nouvelles Questions Féministes 27 (2008b) 4-15

Kruijver, Frank P. M./Jiang-Ning Zhou/Chris W. Pool/Michael A. Hofman/Louis J. G. Goreen/ Dick F. Swaab, "Male-to-Female Transsexuals Have Female Neuron Numbers in a Limbic Nucleus", J Clin Endocrinol Metab 85 (2000) 2034-2041

Lee, Peter A./Christopher P. Houk/S. Faisal Ahmed/Ieuan A. Hughes, in collaboration with the participants in the International Consensus Conference on Intersex organized by the Lawson Wilkins Pediatric Endocrine Society and the European Society for Paediatric Endocrinology, "Consensus Statement on Management of Intersex Disorders", Pediatrics 118 (2006) 488-500

LeVay, Simon, "A Difference in Hypothalamic Structure Between Heterosexual and Homosexual Men”, Science 254 (1991) 1034-1037

LeVay, Simon/Dean H. Hamer, "Evidence for a Biological Influence in Male Homosexuality" Sci Am (1994) 44-49

Money, John W., "Sex Hormones and Other Variables in Human Eroticism”, in:William C. Young (ed.), Sex and Internal Secretions (Baltimore 1961) 1383-1400

Money, John, "Prenatal Hormones and Postnatal Socialization in Gender Identity Differentiation”, Neb Symp Motiv 21 (1973) 221-295

Money, John, “Ablatio Penis: Normal Male Infant Sex-Reassigned as a Girl”, Arch Sex Behav 4 (1975) 65-71

Money, John, Love and Love Sickness: The Science of Sex, Gender Difference, and Pair-Bonding (Baltimore and London 1981 [1980])

Money, John/Anke A. Ehrhardt, Man and Woman, Boy and Girl (Baltimore 1972)

Money, John/Joan G. Hampson/John L. Hampson, "An Examination of some Basic Sexual Concepts:The Evidence of Human Hermaphroditism”, Bull Johns Hopkins Hosp 97 (1955a) 301-319

Money, John/Joan G. Hampson/John L. Hampson, "Hermaphroditism: Recommendations Concerning Assignment of Sex, Change of Sex and Psychological Management", Bull Johns Hopkins Hosp 97 (1995b) 284-300

Phoenix, Charles H., "Hypothalamic Regulation of Sexual Behavior in Male Guinea Pigs", J Comp Physiol Psychol 54 (1961) 72-77

Phoenix Charles H./Robert W. Goy/Arnold A. Gerall/William C. Young, "Organizing Action of Prenatally Administered Testosterone Propionate on the Tissues Mediating Mating Behavior in the Female Guinea Pig", Endocrinology 65 (1959) 369-382

Swaab Dick F./Michel A. Hofman, "Sexual Differentiation of the Human Hypothalamus in Relation to Gender and Sexual Orientation", Trends Neurosci 18 (1995) 264-270 
van den Wijngaard, Marianne, Reinventing The Sexes. The Biomedical Construction of Femininity and Masculinity (Bloomington 1997)

Wilkie, A. O. M./F. M. Campbell/P. Daubeney/D. B. Grant/R. J. Daniels/M. Mullarkey/N. A. Affara 4/M. Fitchett/S. M. Huson, "Complete and Partial XY Sex Reversal Associated with Terminal Deletion of 10q: Report of 2 Cases and Literature Review", Am J Med Genet 46 (1993) 597-600

Young, William C., "The Hormones and Mating Behavior", in: William C. Young (ed.), Sex and Internal Secretions (Baltimore 1961) 1173-1239

Young, William C./Robert W. Goy/Charles H. Phoenix, "Hormones and Sexual Behavior", Science 143 (1964) 212-218

Zderic, Stephen A./Douglas A. Canning/Michael C. Carr/Howard McC. Snyder (eds), Pediatric Gender Assignment: A Critical Reappraisal (New York 2003)

Zhou, Jiang-Ningg/Michel A. Hofman/Louis J. Gooreen/Dick F. Swaab, "A Sex Difference in the Human Brain and its Relation to Transsexuality", Nature 378 (1995) 68-70

106 Gesnerus 68 (2011) 